\title{
Management of Heparin-Induced Thrombocytopenia in Uremic Patients with Hemodialysis
}

\author{
Takefumi Matsuo \\ Hyogo Prefectural Awaji Hospital, Sumoto
}

Japan

\section{Introduction}

Unfractionated heparin is the most commonly used anticoagulant for hemodialysis (HD) (Sonawane et al., 2006). It is well-known that heparin can cause immune-mediated thrombocytopenia due to immunoglobulin antibody formation against the complex of platelet factor 4 (PF4) and heparin. Heparin may also contribute to HD-associated platelet activation, thrombocytopenia, and increased PF4 release from platelets during a heparin dialytic session (Matsuo et al., 1986). Typically, IgG isotype HIT antibodies develop after 514 days of heparin exposure. The incidence of heparin-induced thrombocytopenia (HIT) was estimated at $3.9 \%$ in newly treated hemodialysis patients (Yamamoto et al., 1996). Also, dialysis is often complicated by clotting of the dialysis lines and/or dialyzer due to hypercoagulation regardless of the etiology. When a diagnosis of HIT based on clinical symptoms of thrombocytopenia and immunoassay for PF4/heparin complex antibodies is employed, it remains unclear whether a few patients have HIT. An antigen-based immunoassay to detect the presence of antibodies in a patient's circulation that binds to the PF4/heparin complex is highly sensitive but less specific. Thus, the serological diagnosis of HIT needs to be confirmed by employing a functional assay such as ${ }^{14} \mathrm{C}$-serotonin release assay and heparin-induced platelet aggregation test. The enzyme-linked immunosorbent assay (ELISA) usually detects antibodies of three classes of isotype (IgG, IgA, and IgM) regardless of the capability of these antibodies to activate platelets. There is a way to improve the specificity based on only IgG class antibodies having the capability of inducing platelet activation by heparin (Chang et al., 2006; Syed \& Reilly, 2009).

There are two kinds of dialysis-related complication: unexpected clotting in the circuit and abrupt fistula thrombosis. The former seems to be more frequent in HIT patients than that in non-HIT patients. Visible clotting in the extracorporeal circulation can provide a clue to suspect HIT. AVF thrombosis is also observed in both HIT and non-HIT patients. After starting heparin, the sudden onset of fistula closure is rare as HIT-complicated thrombosis (O'Shea et al., 2002; Nakamoto et al., 2005).

HD patients who develop HIT require not only the discontinuation of heparin, but essentially also the introduction of alternative anticoagulant therapy. An alternative anticoagulant, such as citric acid, and some therapeutic methods, such as heparin-free 
dialysis and peritoneal dialysis, have been employed for patients who require dialysis. However, these therapeutic modalities are unlikely to be beneficial because of the absence of evidence for long-term management.

Regarding clinical evidence to support HIT, a non-heparin anticoagulant should be started with an alternative to heparin. Argatroban rather than lepirudin is recommended as elimination is not via the kidneys, but mainly via the billiary system. As the elimination of lepirudin mainly depends on the renal function, it is not easy to monitor the optimal dose of lepirudin in each session. However, the dose of argatroban in hepato-renal failure is recognized variably to reduce while avoiding major bleeding in a critical setting (Hurting \& Murray et al., 2007). Nafamostat mesilate, a polyvalent protease inhibitor, is sometimes used as an alternative to heparin in Japan. Although a few patients showed the effective resolution of clotting and a gradual increase of the platelet count to the baseline level in a subsequent session receiving nafamostat mesilate, no clinical trial has ever been carried out to evaluate the efficacy in the management of HIT (Matsuo \& Wanaka, 2008b). Although hemodialysis-related HIT appears in an early session after starting HD with heparin, some patients with the anti-PF4/heparin complex antibodies have a risk of delayed-onset HIT, and they may suffer from HIT after cardiovascular intervention.

\section{Frequency of HIT in dialysis patients}

The frequency of HIT is suggested to be from 1 to $5 \%$ of patients exposed to unfractionated heparin, and significantly lower in patients exposed to low-molecular-weight heparin. As one of the reasons for the various frequencies of HIT, assays used to detect HIT antibodies vary in their specificity and sensitivity. An assay for HIT antibody usually detects both nonpathogenic and pathogenic antibodies irrespective of the presence of thrombocytopenia. The clinical significance without thrombocytopenia in which a patient exhibits a stable titer of long-term HIT antibodies remains unclear, but there is an ongoing survey on whether or not subjects have a risk of thrombosis (Asmis et al., 2008).

Few reports on the frequency of HIT in dialysis patients are known, although heparin is employed as the most useful anticoagulant during dialysis. It was believed that the frequency of HIT would be low in a survey targeting to all dialytic patients including both acute and chronic stages (Hutchison et al., 2005). Two surveys involving different subjects show quite different figures on the frequency of HIT. A relatively high frequency of $3.2 \%$ was reported for newly treated subjects receiving dialysis in three months (Yamamoto et al., 1996), and a low rate frequency of $0.6 \%$ is described in chronic dialysis patients treated for over 3 months (Matsuo et al., 2006). Thus, the frequency of HIT in a dialysis population is different between newly treated and chronic maintained dialytic groups. HIT in the former shows a similar incidence to the heparin-sensitive group, and HIT in the later group is rarely identified as HIT or recurrence of HIT when a patient experiences changes in the immunological tolerance brought about by cardiovascular surgery, orthopedic surgery, and high-dose administration of erythropoietin with an adverse platelet-stimulating reaction.

\section{Clinical manifestations and laboratory testing in HD-HIT patients}

Major clinical manifestations are primary thrombocytopenia and new thrombosis. The onset of thrombocytopenia and/or thrombosis which sometimes complicates before 
thrombocytopenia usually occurs 5-10 days after starting heparin anticoagulation. Although thrombocytopenia is ordinarily defined as a $>50 \%$ fall in the platelet count and below $100 \times 10^{9} / \mathrm{L}$, the definition of HD-HIT is less strict, in the range of a $>30 \%$ fall in the platelet count and below $150 \times 10^{9} / \mathrm{L}$ due to the intermittent use of heparin. Timing of the fall of platelet counts also is likely to delay due to the intermittent heparin use. Thus, no dialytic session day may give a chance of recovering the platelet count, and the timing is usually delayed over 10 days. However, heparin flushing to maintain the patency of the inserted catheter in non-session days sometimes leads to the conventional formation of HIT antibodies (Table 1).

\begin{tabular}{|l|l|l|}
\hline Step & Clinical and Lab. assessment & Action plan \\
\hline 1 & suspicion of HIT & $\begin{array}{l}\text { thrombocytopenia }\left(<150 \times 10^{9} / \mathrm{L} \text {, unexplained }\right. \\
\text { decrease of }>30 \%), \text { timing of over } 5 \text { days, no } \\
\text { other cause of thrombocytopenia or } \\
\text { thrombosis }\end{array}$ \\
\hline 2 & ELISA (IgG, A, M) & $\begin{array}{l}\text { no likelihood of HIT due to a negative } \\
\text { qualitative assay }\end{array}$ \\
\hline 3 & $\begin{array}{l}\text { specific IgG-ELISA } \\
\text { high specificity for platelet-activating } \\
\text { antibodies }\end{array}$ \\
\hline 4 & $\begin{array}{l}14 \text { C serotonin release assay } \\
\text { (platelet aggregation test) }\end{array}$ & $\begin{array}{l}\text { confirmation of HIT as a gold standard test } \\
\text { (not preferable due to being less sensitive) }\end{array}$ \\
\hline 5 & $\begin{array}{l}\text { reassessment of HIT if } \\
\text { necessary }\end{array}$ & $\begin{array}{l}\text { recheck other causes of thrombocytopenia and } \\
\text { thrombosis, assess with alternative therapy }\end{array}$ \\
\hline
\end{tabular}

Table 1. Diagnostic approach to HIT

HIT symptoms may occur more rapidly within $24 \mathrm{hr}$ or less in patients who have had a previous exposure to heparin within the prior 3 months. However, a dialytic patient can experience the onset of acute systemic reaction associated with circuit clotting and a marked drop in the platelet count immediately after a bolus heparin injection at start of the session. In chronic intermittent dialysis, HIT is unlikely to occur after several weeks of heparin exposure.

HIT testing is grouped into two types: 1) detection of immunoglobulin antibody against heparin/PF4 complexes by ELISA as a standard technique, and ELISA is simple to perform, can be done in a few hours, is highly sensitive and less specific for antibody detection. Owing in part to its high sensitivity, ELISA often detects antibodies that would not be positive in ${ }^{14} \mathrm{C}$ serotonin release and may be clinically insignificant. ELISA provides much information about the likelihood that a patient has HIT (Shaheed et al., 2007; Aster RH. 2010), and 2) functional assays for the detection of platelet-activating immunoglobulin $G$ by ${ }^{14} \mathrm{C}$ serotonin release. ELISA permits the identification of three subclasses of immunoglobulin: IgG, IgA, and IgM, reacting with PF4/heparin complexes in a solid-phase plate. To avoid the overdiagnosis of HIT, the pathogenic impact of HIT antibodies should be considered if the optical density is $\geq 0.4$ (Warkentin et al., 2008). Therefore, a negative result 
excludes the diagnosis of HIT. ELISA detects together with IgA and IgM antibodies that do not react on FcyIIA-mediated platelet activation. Specific IgG-HIT antibodies can contribute to the interaction of the HIT antibody/PF4/heparin complexes with the Fc $r$ IIA receptor, and subsequently induce platelet activation and the release of microparticles. A high-titer of IgG antibodies is accountable for HIT as well (EI-Shahawy et al., 2007; Carrier et al., 2008).

The ${ }^{14} \mathrm{C}$ serotonin release assay is the gold standard because of its high sensitivity and specificity. Thus, the ${ }^{14} \mathrm{C}$ serotonin release assay should be performed to confirm the diagnosis if a weak positive result is obtained using ELISA (Sheriden et al., 1986; Pouplard et al., 1999). For the assessment of HD-HIT, the pretest probability of the diagnosis of HIT (4T's test) has not been elucidated whether clot formation in the extracorporeal circulation is the first sign of HIT (Weiss et al., 2007). Sudden unexpected clotting in the circuit often provides an important clue for HIT diagnosis despite of there being many causes of clotting during dialysis. After changing the clotted dialyzer and circuit to new ones, dialysis must be restarted with an alternative to heparin, and the planned treatment modality can be uneventfully completed. Subsequent sessions will never affect re-clotting and the recurrence of thrombocytopenia under adequate switching to non-heparin anticoagulation. Furthermore, the patient is more likely to have HIT in the presence of a comparable HITantibody seroconversion. Clotting of the extracorporeal circuit seems to be a manifestation of HIT in the context of primary thrombocytopenia, the visible resolution of clotting with an alternative anticoagulant, HIT antibody formation, and timing within 3 months of starting HD.

Step 1. Recognition of HIT is most important:

1. Unexpected clotting of dialyzer/circuit, and thrombotic occlusion of arteriovenous fistula/grafting despite optimal dose of heparin infusion

2. Absence of other cause of clotting:

slow blood flows, high hematocrit, high ultrafiltration rate, intradialytic blood and blood product transfusion, intradialytic lipid transfusion

3. Check thrombocytopenia

Step 2. Emergent protocol for suspected HIT patient:

1. Stop dialysis immediately, and replace whole extracorporeal circuit with a new one

2. Restart dialysis with argatroban (lepirudin)

3. Confirm by visible inspection that there is no clot in the circuit once starting an alternative to heparin

4. Avoid heparin flush on non-session days

Table 2. Management strategy for HIT in dialytic patients

The clinical features of HIT in dialysis patients includes acute thrombocytopenia that is associated with renal insufficiency except HIT (Oliveria et al., 2008), and repeated clotting of extracorporeal circulation undergoing heparin administration (Lasocki et al., 2008), and the clear disappearance of clots on using an alternative anticoagulant to heparin, and/or, rarely, thrombotic occlusion in AV fistula/grafting (O'Shea et al., 2002, Nakamoto et al., 2005). Circuit clotting occasionally occurs in a routine dialysis procedure, caused by non-HIT 
factors. The causes of clotting are slow blood flow, high hematocrit, high ultrafiltration rate, intradialytic blood and blood product transfusion, intradialytic lipid transfusion. In clinical settings, it is difficult to decide whether the clotted circuit is derived from HIT or not. No differences in the platelet count's fall and timing between clotting-circuit and non-clotting circuit groups have been found in clinical settings. However, a higher level of optical density in ELISA is noted in the clotting patient group. This suggests that HIT antibody formation may be active in the clotting rather than non-clotting patent group (Table 2).

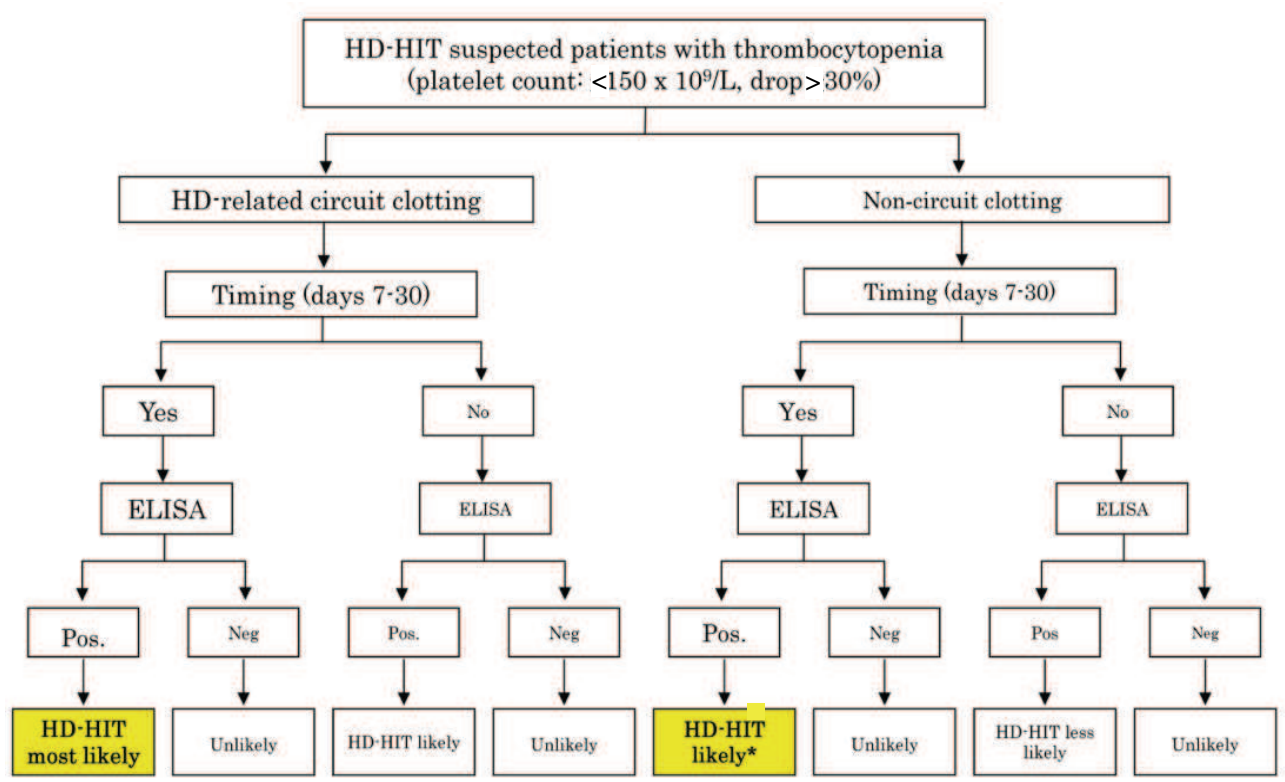

Fig. 1. Algorithm for the diagnosis of HIT in hemodialysis by adding the results of ELISA

\section{Diagnostic approach to HD-HIT patients}

An HD patient associated with HIT is recognized by stepwise assessment. The first step is the evaluation of the platelet count with the definition $\left(<150 \times 10^{9} / \mathrm{L}\right.$ and $\left.>30 \%\right)$. If the patient shows circuit clotting with no other causes, the next step would be to evaluate the timing of thrombocytopenia over days 7-30. The timing of HD-HIT is generally applied over a wider range than usual due to the duration of heparin use always being limited in dialysis of 4-6 hours per day. Positive ELISA added to platelet reduction, the presence of a clotting circuit, and reasonable timing, should be considered as revealing HIT. Thirty six $(92.3 \%)$ of 39 patients with four-factor combinations of thrombocytopenia, clotted circuit, optimal timing of platelet count fall, and positive ELISA had a positive ${ }^{14} \mathrm{C}$ serotonin release assay (Matsuo et al., accepted in Clin Appl Throm/Hemost). According to the algorithm under the condition of no circuit clotting, five $(71.4 \%)$ of 7 patients with thrombocytopenia, reasonable timing, and positive ELISA also had a positive ${ }^{14} \mathrm{C}$ serotonin release assay. In the 
algorithm (Fig. 1), four groups can be identified: HD-HIT is most likely due to a highest positive rate of ${ }^{14} \mathrm{C}$ serotonin release among the four groups, 'HD-HIT most likely'; secondly, HD-HIT is likely to show a relatively high rate on a functional assay, 'HD-HIT likely'. Timing outside the range and a negative ELISA despite the presence of a clotting circuit should be identified as 'unlikely'. 'HD-HIT less likely' without any clotting is rare even though ELISA is positive.

The sudden occurrence of clots in the dialyzer and/or circuit with an unexpected fall in the platelet count between 7 and 30 days are dramatic symptoms of HIT in HD patients undergoing appropriate anticoagulation with heparin. In an HD patient with suspected HIT, the clinical implication of clotting in the circuit as HIT can easily be supported in combination with thrombocytopenia, timing of the platelet fall, and result of ELISA.

\section{Management of HD-HIT patients}

Visible clotting in the circuit, including blood chambers, tubes, and dialyzer, are easily recognized by medical staff in the session, so HIT management can be initiated immediately when the clotting is likely to arise from HD-HIT. Once the HIT diagnosis has been established from high clinical suspicion alone before laboratory confirmation, it is essential that all sources of heparin, including low-molecular-weight-heparin, heparin flushing, and heparin-coated catheters or devices, must be discontinued. The early recognition of HIT in the presence of clot formation in the extracorporeal circuit is critical, and any additional infusion of heparin on the misunderstanding of heparin shortage must be contraindicated to resolve the clot. When the dialytic procedure cannot be continued with circuit clotting, a new dialyzer and devices of the extracorporeal circuit must be set up, and the session must be immediately restarted with an alternative anticoagulant. Then, the diagnosis of HIT can be verified using the algorithmic assessment in Fig. 1 and Table 2.

Established alternative anticoagulation in HD patients with HIT is conducted with danaparoid, lepirudin, and argatroban. Danaparoid is a low- molecular-weight heparinoid. Although danaparoid is the most widely used for HD-HIT patients, it does not exhibit proper anticoagulation for HD-HIT due to clinically relevant cross-reactivity. Lepirudin is a recombinant hirudin preparation. Adequate dose adjustment is very difficult in for HD-HIT patients, in which it is cleared mainly by the kidneys and its half-life is markedly long in uremic patients.

Argatroban (formerly called MD805), a synthetic direct thrombin inhibitor, is nonimmunogenic and does not show cross-reactivity with HIT antibodies. In contrast to lepirudin, argatroban is primarily hepatically metabolized, and its half-life is moderately extended in HD patients (Matsuo et al., 1988; Matsuo et al., 1990). Argatroban as an alternative anticoagulant is predominantly used for the prevention of extracorporeal circuit clotting in HD-HIT patients at the initial dose of $250 \mu \mathrm{g} / \mathrm{kg}$ at the start of dialysis, and followed by a continuous infusion of at $2 \mu \mathrm{g} / \mathrm{kg} / \mathrm{min}$ while the hepatic function is normal. Dose adjustment is conducted for an empirical target of a 1.5-3.0-fold prolongation of the activated partial thromboplastin time (APTT) test, as an equivalent to the prolongation of heparin therapy. This dose can be reduced to $<2 \mu \mathrm{g} / \mathrm{kg} / \mathrm{min}$ with a $1.5-2.5$-fold prolongation of the APTT after the acute phase of HIT has subsided. The dose should also be reduced to 
$<2 \mu \mathrm{g} / \mathrm{kg} / \mathrm{min}$ depending on the severity hepatic dysfunction to avoid unexpected hemorrhagic complications. Only the replacement of heparin with argatroban in dialysis can lead to recovery from symptoms of HIT (Gozdzikiewicz et al., 2007; Roncon-Albuquerque et al., 2010; Matsuo \& Wanaka, 2008a). Despite there being no apparent evidence for the systemic administration of argatroban on non-session days, argatroban anticoagulation may be useful to prevent the risk of new and worsening thrombotic events. When an HD-HIT patient is in a hypercoagulable state, such as with an elevated level of plasma D-dimer, argatroban therapy seems to be essential. The empirical dose of the drug is estimated to $0.7 \mu \mathrm{g} / \mathrm{kg} / \mathrm{min}$ in patients with a normal liver function and $0.2 \mu \mathrm{g} / \mathrm{kg} / \mathrm{min}$ in those with hepatic dysfunction or a risk of bleeding. Future studies should be done on how to apply the drug on non-session days (Hursting \& Murray et al., 2008).

Nafamostat mesilate, a polyvalent synthetic protease inhibitor, is employed as a regional anticoagulant in dialysis patients with bleeding risks as an alternative to heparin in Japan. The drug has no influence on the systemic blood coagulation cascade due to its very short half-life, within $10 \mathrm{~min}$, about $40 \%$ of the drug is removed from the dialyzer, and there is no cross-reactivity with HIT antibodies. Despite the fact that the HD-HIT session is uneventfully completed using nafamostat mesilate, it remains why the drug has a therapeutic benefit on the resolution of HIT over the effect of heparin cessation (Matsuo et al., 2001; Matsuo \& Wanaka, 2008b)

\begin{tabular}{|c|c|c|c|c|c|c|c|c|c|}
\hline & \multirow[t]{2}{*}{ Age/sex } & \multirow[t]{2}{*}{$\begin{array}{l}\text { Type of } \\
\text { surgery }\end{array}$} & \multirow{2}{*}{$\begin{array}{l}\text { Thrombocytopenia } \\
\text { ( } 50 \% \text { fall, } 5-10 \text { days } \\
\text { from pre-op. level) }\end{array}$} & \multicolumn{3}{|c|}{$\begin{array}{l}\text { Immunoassay } \\
\text { (pos >0.4 OD) }\end{array}$} & \multicolumn{2}{|c|}{$\begin{array}{l}\text { Functional } \\
(\text { pos }>20 \%)\end{array}$} & \multirow{2}{*}{$\begin{array}{l}\text { assay } \\
\text { 14days }\end{array}$} \\
\hline & & & & Pre & 7days & 14days & Pre & 7days & \\
\hline 1 & $58 / \mathrm{M}$ & $\begin{array}{c}\text { aortic } \\
\text { aneurysm } \\
\text { grafting }\end{array}$ & $-*$ & -** & 1.82 & 2.39 & $-* * *$ & - & 96 \\
\hline 2 & $67 / \mathrm{M}$ & $\begin{array}{c}\text { aortic } \\
\text { aneurysm } \\
\text { grafting }\end{array}$ & $+(56.6 \%)$ & - & - & - & - & - & - \\
\hline 3 & $63 / \mathrm{M}$ & CABG & - & - & - & - & - & - & - \\
\hline 4 & $69 / \mathrm{M}$ & CABG & $+(69.6 \%)$ & - & - & - & - & - & - \\
\hline 5 & $55 / \mathrm{M}$ & CABG & - & - & - & - & - & - & - \\
\hline 6 & $60 / F$ & CABG & $+(73.5 \%)$ & - & - & - & - & - & - \\
\hline 7 & $63 / \mathrm{M}$ & valve op. & - & - & - & - & - & - & - \\
\hline 8 & $70 / \mathrm{M}$ & CABG & - & 1.28 & 1.87 & 2.01 & - & 65 & 68 \\
\hline
\end{tabular}

${ }^{*}$ not consistent with platelet criteria

${ }^{* *}$ optical density $<0.4$ by ELISA

*** radioactive serotonin release under $20 \%$

Table 3. Seroconversion in cardiac surgery patients with chronic hemodialysis 


\section{Cardiovascular surgery with chronic hemodialysis}

Chronic dialysis patients who repeatedly exposed to heparin rarely are at risk of developing HIT, show high-level mortality due to atherosclerotic cardiovascular events (Mureebe et al., 2004). Sometimes they have indications for cardiovascular surgery on non-dialysis sessions. There are few data available on whether long-term heparin usage affects post-operative seroconversion, and the development of HIT. Surgical procedures usually stimulate the release of PF4 from platelets and the endothelium. PF4 does certainly facilitate complex formation in the presence of a dynamic equilibrium with external heparin. Macromolecular $\mathrm{PF} 4 /$ heparin complexes stimulate the immunomediated production of anti-PF4/heparin complex antibodies. Increased levels of immunomediated HIT-antibody production are occasionally recognized in the post-operative period. Although a high rate of seroconversion appears to be involved in the development of HIT, most seroconversion shows a lack of thrombocytopenia, and very few patients with seroconversion develop HIT.

In cardiovascular patients receiving regular dialysis, the risk of HIT is presumed to increase in certain situations, such as cardiac interventions, by the modification of immunological tolerance to PF4/heparin complexes. Eight of 79 patients with cardiovascular surgery were treated with dialysis (Table 2). Two patients with neither thrombocytopenia nor thrombosis experienced seroconversion with the development of positive ELISA and SRA. One patient was negative in the pre-operative state despite heparin dialysis for 3.5 years. He may have undergone a resetting of the immunologic response to PF4/heparin complexes due to the influence of perioperative surgical procedures (case \#1 in Table 3). The other patient had pre-existing HIT antibodies on ELISA, and the positive SRA would be induced by accelerating the production of HIT antibodies due to cardiac intervention (case \#8 in Table 3). Although no 'true HIT' patient could be found in the series, this suggests that reactivation of the immune system could be functioning in the perioperative period, and the risk of developing HIT may be continuing until subsidence of HIT antibody production. Any thrombocytopenia corresponding to HIT criteria could not be detected with the monitoring of platelet counts in post-operation, despite a marked fall within 4 postoperative days, and steeply increasing platelet counts in the following days were observed regardless of whether or not the patients experienced seroconversion.

Post-operative thrombocytosis, in contrast to HIT-related thrombocytopenia, can influence the results of platelet counts, because marked thrombocytosis must compensate for thrombocytopenia derived from immune-mediate platelet consumption. When the recovery of platelet counts remains low over the $5^{\text {th }}$ post-operative day and an abrupt platelet fall is induced by the reuse of heparin, HIT should be considered in patients with no other cause of thrombocytopenia.

HD patients with both positive ELISA and serotonin release assay and without defined thrombocytopenia may have a risk of developing HIT through re-exposure to heparin in a restarted dialysis session. A clotting circuit recognized as atypical HIT-related thrombosis is causally linked to the onset of thrombocytopenia, and the event will be certainly resolved by employing an alternative to heparin. HIT may occur even after years of uneventful chronic intermittent hemodialysis due to resetting of the immune mechanism triggered in cardiac surgery, catheter intervention, and, rarely, a platelet-activating procedures and agents. 


\begin{tabular}{|c|c|c|c|c|c|c|}
\hline & $\begin{array}{l}\text { Symptoms of acute } \\
\text { systemic reaction }\end{array}$ & $\begin{array}{l}\text { Circuit } \\
\text { clotting }\end{array}$ & $\begin{array}{l}\text { AVF } \\
\text { thrombus }\end{array}$ & $\begin{array}{l}\text { Platelet } \\
\text { count } \\
\left(\times 10^{9} / \mathrm{L}\right) \\
\text { at ASR }\end{array}$ & $\begin{array}{l}\text { Maximum } \\
\text { fall (\%) in } \\
\text { platelet } \\
\text { count }\end{array}$ & $\begin{array}{l}\text { Timing of } \\
\text { platelet } \\
\text { fall ( days) }\end{array}$ \\
\hline 1 & Dyspnea, chills, fever & $+* *$ & - & 53 & 85 & 14 \\
\hline 2 & Nausea, vomiting & - & + & 25 & 88 & 12 \\
\hline $3^{*}$ & $\begin{array}{c}\text { Dyspnea, flushing, chills, } \\
\text { fever, }\end{array}$ & - & - & 16 & 90 & 13 \\
\hline 4 & Dyspnea, chest pain & + & - & 28 & 94 & 7 \\
\hline 5 & $\begin{array}{l}\text { Dyspnea, chest pain, } \\
\text { hypotension, nausea, } \\
\text { vomiting }\end{array}$ & - & + & 84 & 72 & 13 \\
\hline $6^{*}$ & Dyspnea, fever & + & - & 57 & 67 & 8 \\
\hline $7^{* * *}$ & Dyspnea, chills, nausea & + & - & 92 & 80 & 11 \\
\hline 8 & $\begin{array}{l}\text { Dyspnea, chills, fever, } \\
\text { chest pain, nausea }\end{array}$ & + & - & 74 & 73 & 11 \\
\hline
\end{tabular}

*diagnosed with pseudo-pulmonary embolism, ${ }^{* *}$ unexpected closure of hollow fibers of dialyzer with fibrin-platelet aggregates in two consecutive sessions, ${ }^{* * *}$ heparin flushing on non-session day.

Table 4. Eight patients with HIT-induced acute systemic reaction from twenty-seven dialytic patients who experienced some acute systemic reactions

\section{Characteristics of acute systemic reaction in dialytic patients}

Infrequently, an acute systemic reaction (ASR) as a manifestation of HIT occurs 5-30 min after heparin bolus administration at the start of dialysis. The symptoms are fever, chills, and flushing as acute inflammatory reactions, and hypertension, tachycardia, dyspnea, chest pain, and cardiopulmonary arrest. Although hypertension is usually associated with ASR (Warkentin et al., 2009), in contrast, acute hypotension often occurs as a sign of cardiovascular collapse during dialysis. When dyspnea as the cardiorespiratory reaction in ASR is prominent, it is considered to be a pseudo-pulmonary embolism (Tejedor Alonso et al., 2005; Hartman et al., 2006; Matsuo et al., 2007). However, the signs and symptoms are very similar to those in dialyzer reactions, dialytic complications as disequilibrium syndrome, and circuit clotting during the HD procedure. Except for platelet reduction by heparin, it is difficult to determine whether symptoms of ASR are most likely to be due to HIT in clinical settings. There are two causes of hypotension: HIT-induced hypotension may associate with cardiorespiratory collapse due to pseudo-pulmonary embolism, and HDinduced hypotension often with nausea and vomiting, and occasionally with back pain and syncope.

As the clinical features of eight patients defined with HIT-induced ASR from twenty-seven patients who experienced some ASR, seven of the eight patients suffered from dyspnea, and two ASR patients (case \#3, \#6 in Table 4) showing hypoxia, no radiological evidence, and 
the quick recovery of symptoms after the cessation of heparin were defined as pseudopulmonary embolism. Hypotension was implicated when pulmonary collapse was noted in a patient (case \#5 in Table 4). Thus, hypotension was not a primary feature of the HITinduced acute systemic reaction. However, no hypertension appeared in eight HIT-induced ASR patients. Either complications of circuit clotting or AVF thrombus formation appeared in seven patients excluding a case (case \#3 in Table 4) of pseudo-pulmonary embolism. The platelet fall rate and timing in HIT-induced ASR cannot be differentiated from those of HDinduced ASR (Table 4). Complications during dialysis including dialyzer reactions, clotting circuit, anticoagulation failure, and hypotension may mimic the signs and symptoms of HIT-induced ASR except hypotension. Thus, a platelet count and assays for HIT antibodies should be considered for diagnosing acute HIT when HD patients show an abrupt fall in platelet counts and clinical symptoms of ASR with an unknown cause during dialysis. The results of the HIT-antibody assay showed that the differential diagnosis would be straightforward regarding whether HD patients with thrombocytopenia suffered from HITinduced or HD-complicated ASR.

\section{$\downarrow$ HIT in HD}

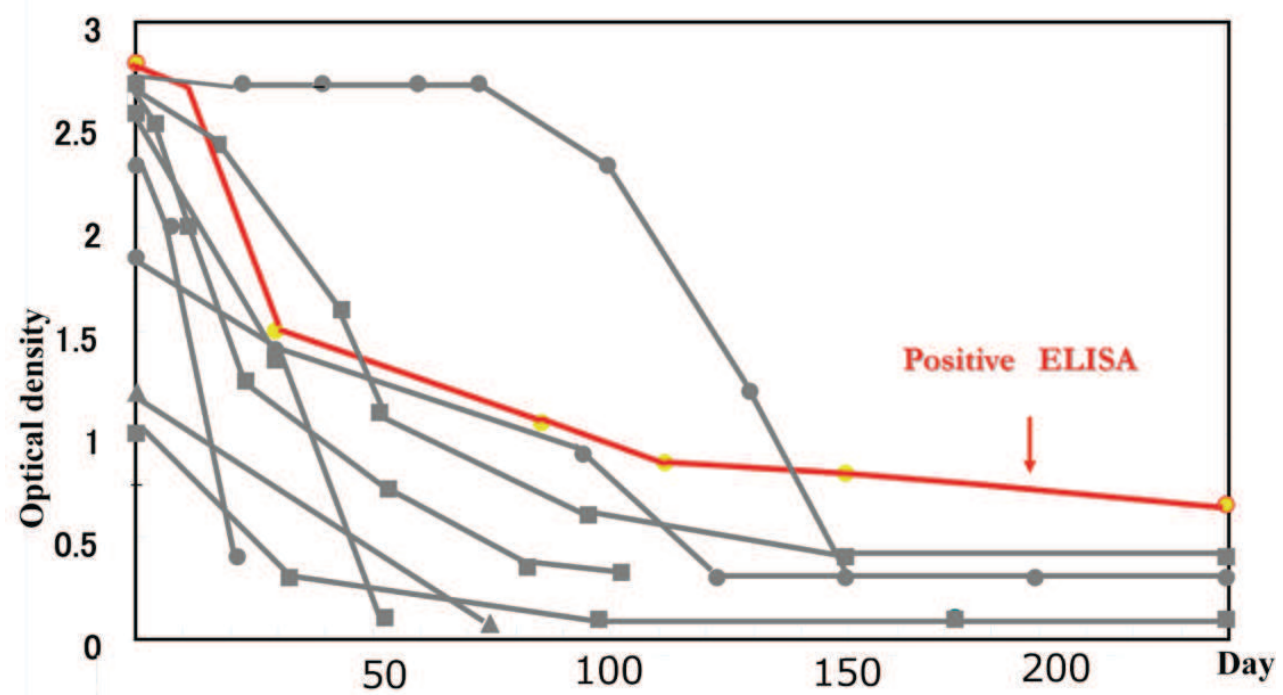

Fig. 2. Reduction in optical density of ELISA after heparin cessation in HD-HIT

\section{Reexposure to heparin}

The principal of heparin reexposure is based on a characteristic immune response in T-cell independent B-cell activation because of lack of a strong memory response, perhaps explaining transience and lack of anamnesis of the anti PF4/heparin immune response (Selleng et al., 2010). The reexposure can be carried out with lack of immune memory for the PF4/heparin complex antigen in patients with previous episodes of HIT when their HIT antibodies become negative. Currently, there is no clinical consensus regarding reexposure to heparin for HIT. However, it reexposure is needed at least 100 days after no detection of 
HIT antibodies by ELISA. Reductions in the optical density of ELISA are quite variable after the cessation of heparin (Fig. 2). While a positive ELISA continues long-term over years marked as positive ELISA is also recognizable in Fig.2, a short span type is also contained. Since the various half-life of HIT antibodies may reflect the existence of different properties of HIT antibodies, each patient should be followed by ELISA until there is no longer a detection of HIT antibodies. Reexposure to heparin should be introduced under negative ELISA where adequate emergent measures are adopted including platelet counting tests (Matsuo et al., 2003; Davenport et al., 2009; Wanaka et al., 2010). A majority of heparinreexposure patients show no recurrence of HIT unless they undergo cardiovascular surgery, catheter intervention, and, rarely, receive platelet-stimulating drugs. Reexposure to heparin in HD patients carrying a stable titer with an optical density over 0.4 may not be allowed because the risk of recurrence of HIT is likely to increase on heparin reuse.

\section{Conclusion}

HD-HIT is a drug-induced, immunoglobulin-mediated disorder that it is suspected in dialytic patients with an unexpected fall in the platelet count, and/or unexplained thrombotic events, particularly visible clotting in the circuit under an adequate heparin dose, and that begins between 5 and 10 days (nadir between 7 and 30 days, mostly by the third to fifth session) after heparin initiation. Although a positive result of HIT antibodies is presumably detected by sensitive ELISA, the diagnosis should be confirmed, whenever possible, using a functional assay. Immediately after the clinical suspicion of HIT, all sources of heparin should be discontinued including heparin used to flush or lock catheters. Alternative non-heparin anticoagulants, preferentially in a direct thrombin inhibitor, should be restarted for dialysis. Early treatment is important as thrombus formation including a clotting circuit may complicate at a high rate in 30 days after the cessation of heparin. Argatroban as an alternative to heparin must contribute to the quick recovery of the platelet count and immediate disappearance of circuit clotting. A steady decrease of the ELISA titers can be expected after heparin discontinuation. A negative seroconversion of HIT antibodies is usually observed by $\sim 30$ to more than 100 days after the discontinuation. Reexposure to heparin can be selected at the same dose of heparin as used before the onset of HIT. Small peak of HIT antibodies may often appear after exposure, but a follow-up of the antibody titers does not reach a threshold to induce the recurrence of HIT. When HD-HIT patients exhibit a high risk of thrombotic formation or worsening thrombosis, the same alternative anticoagulant therapy may be needed in non-session days.

\section{References}

Asmis LM, Segal JB, Plantnga LC, Fink NE, Kerman JS, Kickler TS, Coresh J, Gardner LB. (2008) Heparin-induced antibodies and cardiovascular risk in patients on dialysis. Thromb Haemost 100: 498-504.

Aster RH. Improving specificity in HIT testing. Blood 2010; 116: 1632-1633.

Chang JJ, Parikh CR. (2006) When heparin causes thrombosis: significance, recognition, and management of heparin-induced thrombocytopenia in dialysis patients. Semin Dial 19: 297-304. 
Carrier M, Rodger MA, Fergusson D, Doucette S, Kovacs MJ, Moore J, Kelton JG, Knoll GA. (2008) Increased mortality in hemodialysis patients having specific antibodies to the platelet factor 4-heparin complex. Kidney Int 73: 213-219.

Davenport A. Sudden collapse during haemodialysis due to immune-mediated heparininduced thrombocytopenia. (2006) Nephrol Dial Transplant 21: 1721-1724.

Davenport A. (2009) Antibodies to heparin-platelet factor 4 complex: pathogenesis, epidemiology, and management of heparin-induced thrombocytopenia in hemodialysis. Am J Kidney Dis, 54; 361-374

EI-Shahawy, M, Noureddin M, Abdullah H, Mack WJ, Calverley DC. (2007) Platelet FcgammaRIIA receptor surface expression is increased in patients with ESRD and is associated with atherosclerotic cardiovascular events. Am J Kidney Dis 49: 127134.

Gozdzikiewicz J, Borawski J, Mysliwiec M. (2007) Treatment of heparin-induced thrombocytopenia type II in hemodialysis patients: the search for a holy grail continues. Clin Appl Thromb/Hemost 13:110-111.

Holmes CE, Huang JC, Cartelli C, Howard A, Rimmer J, Cushman M. (2009) The clinical diagnosis of heparin-induced thrombocytopenia in patients receving continuous renal replacement therapy. J Thromb Thromboly 27:406-412.

Hartman V, Malbrain M, Daelemans R, Meersman P, Zachee P. (2006) Psudo-pulmonary embolism as a sign of acute heparin-induced thrombocytopenia in hemodialysis patients: safety of resuming heparin after disappearnance of HIT antibodies. Nephron Clin Pract 104:c143-148.

Hursting M, Murray P. (2008) Argatroban anticoagulation in renal dysfunction: a literature analysis. Nephron Clin Pract 109:c80-c94.

Hutchison CA, Dasgupta I. (2005) National survey of heparin-induced thrombocytopenia in the haemodialysis population of the UK population. Nephrol Dial Transplant 20: 444-446.

Lasocki S, Piednoir P, Ajzenberg N, Geffroy A, Benbara A, Montravers P. (2008) Anti$\mathrm{PF} 4 /$ heparin antibodies associated with repeated hemofiltration-filter clotting: a retrospective study. Crit Care 12(3) R84 Epub.

Matsuo T, Chikahira Y, Yamada Y, Nakao K, Uesima S, Matsuo O. (1988) Effect of synthetic thrombin inhibitor (MD805) as an alternative drug on heparin induced thrombocytopenia during hemodialysis. Thromb Res 52; 165-171.

Matsuo T, Yamada T, Yamanashi T, Ryo R. (1990) Anticoagulant therapy with MD805 of a hemodialysis patient with heparin-induced thrombocytopenia. Thromb Res 58; 663-666.

Matsuo T, Matsuo M, Ouga-Maruyama S. Can nafamostat mesilate be used for temporary management of hemodialysis in a patient with heparin-induced thrombocytopenia (HIT)? (2001) Thromb Haemost 86; 1115-1116.

Matsuo T, Matsuo M, Wanaka, K, Sakai R. (2003) Heparin re-exposure after heparin-induced thrombocytopenia in a chronic hemodialysis patient. Clin Lab Haematol 25: 333334.

Matsuo T, Kobayashi H, Matsuo M, Wanaka K, Nakamoto H, Matsusima H, Sakai R. (2006) Frequency of anti-heparin-PF4 complex antibodies (HIT antibodies) in uremic patients on chronic intermittent hemodialysis. Pathphysiol Haemost Thromb; 35:445-450. 
Matsuo T, Kusano H, Wanaka K, Ishihara M, Oyama A. (2007) Heparin-induced thrombocytopenia in a uremic patient requiring hemodialysis: an alternative treatment and reexposure to heparin. Clin Appl Thromb Hemost. 13:182-7

Matsuo T, Wanaka K. Hemodialysis and argatroban. (2008a) Semin Thromb Hemost 34 (Suppl 1); 56-61.

Matsuo T, Wanaka K. Management of uremic patients with heparin-induced thrombocytopenia requiring hemodialysis. (2008b) Clin Appl Thromb Hemost 14; 459-464.

Mureebe L, Coats RD, Silliman WR, Shouster TA, Nichols WK, Silver D. (2004) Heparinassociated antiplatelet antibodies increase morbidity and mortality in hemodialysis patients. Surgery 136:848-853.

Nakamoto H, Shimada Y, Kanno T, Wanaka K, Matsuo T, Suzuki H.(2005) Role of platelet factor 4-heparin complex antibody (HIT antibody) in the pathogenesis of thrombotic episodes in patients on hemodialysis. Hemodial Int 9(suppl 1):s2-5.

O'Shea SI, Sands JJ, Nudo SA, Ortel TL. (2002) Frequency of anti-heparin-platelet factor 4 antibodies in hemodialysis patients and correlation with recurrent vascular thrombosis. Am J Hematol 69:72-73.

Oliveria GBF, Crespo EM, Becker RC, Honeycutt EF, Abrams CS, Anstrom KJ, Berger PB, Davidson-Ray LD, Eisenstein EL, Kleiman NS, Moliterno DJ, Moll S, Rice L, Rodgers JO, Steinhubl SR, Tapson VF, Ohman EM, Granger CB. (2008) Incidence and prognostic significance of thrombocytopenia in patients treated with prolonged heparin therapy. Arch Intern Med 168:94-102.

Pouplard C, Amiral J, Borg JY, Laporte-Simitsidis S, Delahousse B, Gruel Y. (1999) Decision analysis for use of platelet aggregation test, carbon 14-serotonin release assay, and heparin-platelet factor 4 enzyme-linked immunosorbent assay for diagnosis of heparin-induced thrombocytopenia. Am J Clin Pathol 111:700-706.

Roncon-Albuquerque R, Beco A, Ferreira AL, Gomes-Carvalho C, Costa A, Frazao J, Pestana M, von Hafe P. (2010) Therapeutic implications of heparin-induced thrombocytopenia complicating acute hemodialysis. Clin Nephrol 73: 326-330.

Selleng K, Schutt A, Selleng S, Warkentin TE, Greinacher A. Studies of the anti-PF4/heparin immune response: adapting the enzyme-linked immunosorbent spot assay for detection of memory B cells antigens. (2010) Transfusion 50; 32-39.

Shaheed G, Malkovska V, Mendoza J, Patel M, Rees J, Wesley R, Merryman P, Horne M. (2007) PF4 ENHANCD assay for the diagnosis of heparin-induced thrombocytopenia in complex medical and surgical patients. Crit Care Med 35:1784-1785.

Sheriden D, Carter C, Kelton JG. (1986) A diagnostic test for heparin-induced thrombocytopenia. Blood 67: 27-30.

Sonawane S, Kasbekar N, Berns JS. (2006) The safety of heparins in end-stage renal disease. Semin Dial 19:305-310.

Syed S, Reilly RF. (2009) Heparin-induced thrombocytopenia: a renal perspective. Nat Rev Nephrol 5: 501-511.

Tejedor Alonso, MA, Revuelta Lopez K, Garcia Bueno MJ, Casas L,Osada ML, Ingelmo Rosado A, Gruss Vergara E, Vila Albelda C, Moro Moro M. (2005) Thrombocytopenia and anaphylaxis secondary to heparin in a hemodialysis patient. Clin Nepherol 63: 236-240 
Warkentin TE, Sheppaed JI, Moore JC, Sigouin CS, Kelton JG. (2008) Quantitative interpretation of optical density measurements using PF4-dependent enzymeimmunoassays. J Throm Haemost 6: 1304-1312.

Warkentin TE, Greinacher A. (2009) Heparin-induced anaphylactic and anaphylactoid reactions: two distinct but overlapping syndromes. Expert Opin Drug Saf 8; 129144.

Wanaka K, Matsuo T, Matsuo M, Kaneko C, Miyasita K, Asada R, Matsusima H, Nakajima Y. (2010) Re-exposure to heparin in uremic patients requiring hemodialysis with heparin-induced thrombocytopenia. J Thromb Haemost 8; 616-618.

Weiss BM, Shumway NM, Howard RS, Ketchum LK, Reid TJ. (2008) Optical density values correlate with the clinical probability of heparin-induced thrombocytopenia. J Thromb Thrombolysis 26; 26: 243-247.

Yamamoto S, Koide M, Matsuo M, Suzuki S, Ohtaka M, Saika S, Matsuo T. (1996) Heparininduced thrombocytopenia in hemodialysis patients. Am J Kidney Dis 28:82-85. 


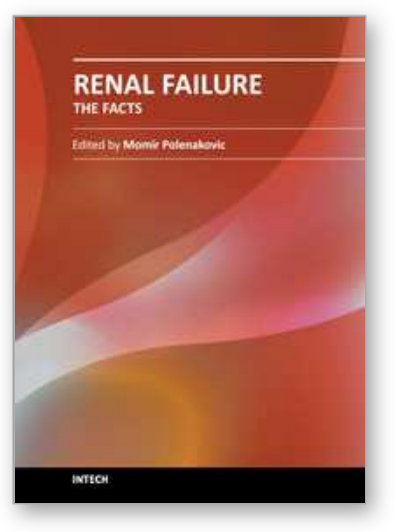

\author{
Renal Failure - The Facts \\ Edited by Dr. Momir Polenakovic
}

ISBN 978-953-51-0630-2

Hard cover, 270 pages

Publisher InTech

Published online 23, May, 2012

Published in print edition May, 2012

The book "Renal Failure - The Facts" consists of some facts about diagnosis, etiopathogenis and treatment of acute and chronic renal failure. Acute, as well as chronic renal failure is great medical problems and their treatment is a burden for the budget of each government. The purpose of the chapters is to present some important issues of diagnosis and causes of AKI, as well as caused by snakes and arthropods, after cardiac surgery, as well as some therapeutic achievements in AKI. Well presented are the psychological condition in patients on haemodialysis, as well as the treatment of diabetic uremics. The book is aimed at clinicians with a special interest in nephrology, but it should also prove to be a valuable resource for any generalists who encounter a nephrological problems in their day-to-day practice.

\title{
How to reference
}

In order to correctly reference this scholarly work, feel free to copy and paste the following:

Takefumi Matsuo (2012). Management of Heparin-Induced Thrombocytopenia in Uremic Patients with Hemodialysis, Renal Failure - The Facts, Dr. Momir Polenakovic (Ed.), ISBN: 978-953-51-0630-2, InTech, Available from: http://www.intechopen.com/books/renal-failure-the-facts/management-of-heparin-inducedthrombocytopenia-hit-in-uremic-patients-with-hemodialysis-hd

\section{INTECH}

open science | open minds

\section{InTech Europe}

University Campus STeP Ri Slavka Krautzeka 83/A 51000 Rijeka, Croatia Phone: +385 (51) 770447 Fax: +385 (51) 686166 www.intechopen.com

\section{InTech China}

Unit 405, Office Block, Hotel Equatorial Shanghai No.65, Yan An Road (West), Shanghai, 200040, China 中国上海市延安西路65号上海国际贵都大饭店办公楼405单元 Phone: +86-21-62489820

Fax: +86-21-62489821 
(C) 2012 The Author(s). Licensee IntechOpen. This is an open access article distributed under the terms of the Creative Commons Attribution 3.0 License, which permits unrestricted use, distribution, and reproduction in any medium, provided the original work is properly cited. 